\title{
ZIKA VIRUS STRATEGIC RESPONSE FRAMEWORK FOR THE GULF STATES-2016: AN URGENT NEED FOR COLLABORATION
}

\author{
By
}

\begin{abstract}
A. A. BINSAEED ${ }^{1}$, M. AL-HAJRI ${ }^{2}$, E. M. NOURELDIN ${ }^{3}$, A. FARAG ${ }^{4}$, S. M. MALIK ${ }^{5}$, M. S. AL-ZEDJALI ${ }^{6}$, R. F. ALHAKEEM ${ }^{7}$, H. AL-ROMAIHI ${ }^{8}$, M. H. ALZAHRANI ${ }^{3}$, and A. A. ALSHEIKH ${ }^{3 *}$

Deputy Minister of Public Health, MoH, Riyadh ${ }^{1}$, Director, Department of Emergency Preparedness and Response, MoPH, Doha ${ }^{2}$, National Center for Vector-borne Diseases, MoH, Jazan ${ }^{3}$, Acting Head, Communicable Diseases Control Programs, MoPH, Doha ${ }^{4}$, Department of Prevention and Control of Communicable Diseases, WHO/EMRO, Cairo ${ }^{5}$, Egypt, Director, Department of Malaria Eradication, Ministry of Health, Muscat ${ }^{6}$, Sultanate of Oman ${ }^{6}$, Director of thelnfectious Diseases Control, MoH, Riyadh ${ }^{7}$, Manager, Department of Health Protection and Communicable Diseases Public Health ${ }^{8}$, Qatar $^{2,4,8}$ and Malaria program director, MoH, Riyadh ${ }^{9}$, Saudi Arabia ${ }^{1,3,7,8}$

( ${ }^{*}$ Correspondence:adelalsheikh@gmail.com)
\end{abstract}

\begin{abstract}
The Zika virus (ZIKV) became the latest threat to global health security when WHO declared on $1^{\text {st }}$ February 2016, that recently reported clusters of microcephaly and other neurological disorders in Brazil constitute a Public Health Emergency of International Concern (PHEIC). These clusters were reported concurrently with an outbreak of ZIKV, which has been ongoing in Brazil and other countries in the America region since 2015. A growing body of clinical and epidemiological data possibly leans towards a causal role for ZIKV as the occurrence of the clusters of microcephaly and other neurological disorders principally the Guillain-Barre' syndrome are associated in time and place with the ongoing ZIKV transmission in the America region. So far, Zika viral transmission has been documented in a total of 69 countries and territories with autochthonous transmission from 2007 to 10 August 2016. The geographical range of ZIKV has been increasing steadily. Considering the presence of competent vectors that transmit ZIKV in some parts of the Gulf countries, and the close relationship with Brazil, a local transmission of the virus is plausible once the virus is introduced through travel. This review suggests the integration of epidemiological and entomological surveillance for monitoring and control of the vectors of ZIKV. The risks associated with ZIKV infection and the possible threat to the Gulf States was described. A strategic Zika response framework (SRF) for the Gulf States has been developed to meet their urgent need for a collaborative and coordinated response for prevention and spread of ZIKV infection. A coordinated response of all partners in the Gulf States across sectors and services at national, as well as, regional levels is required.

Key words: Zika virus, Risks Saudi Arabia, Qatar, Sultanate of Oman
\end{abstract}

\section{Introduction}

Zika virus (ZIKV) was discovered in 1947 in the Zika Forest in Uganda. It is an arbovirus belonging to the family Flaviviridae. Zika infection in human was detected in Uganda and Tanzania (Dick, 1952; Smithburn, 1952), West Africa (Macnamara, 1954), and then spread to Indonesia (Olson, 1981). A large epidemic was described in Yap (Micronesia) in 2007
(Duffy et al, 2009). Since then, ZIKV was expanding in area and had affected Thailand (Buathong et al, 2015), the Philippines (Alera et al, 2015), French Polynesia (Baronti et al, 2014), Easter Island-South Pacific (Tognarelli et al, 2015), and Brazil (Zanluca et al, 2015).

The geographical range of ZIKV has steadily increased. Infection with ZIKV was detected in 69 countries and territories 
up to $10 / 8 / 2016$ including 52 countries with reported autochthonous transmissions (Tab. 1; WHO, 2016a). As of 10 August 2016, microcephaly and other central nervous system (CNS) malformations have been reported in 15 countries or territories, while an increased incidence of Guillain-Barré syndrome (GBS) has been reported from 16 countries and territories worldwide (WHO, 2016a).

During the currently ongoing outbreak, WHO estimates that there would be 3-4 million cases of ZIKV infection (including asymptomatic cases) in south, central, and north America in the next 12 months (Samarasekera and Triunfol, 2016).

1 February 2016, WHO declares that recently, reported clusters of microcephaly and other neurological disorder which is presumed to be associated with ZIKV constitutes a "Public Health Emergency of International Concern" (WHO, 2016b) Therefore, high vigilance is needed as ZIKV is spread continuously to new geographical areas where potential vectors are present (WHO, 2016a).

The Gulf States need to establish regional teams for Zika incident management in order to guide and assist for the implementation of enhanced and effective epidemiological and entomological surveillance, imported cases management, and risk communications for the public concerning travel and trade. A coordinated response of all partners in the Gulf States across sectors and services at national, level is required.

In connection with this, the risks associated with ZIKV infection and the possible threat to the Gulf States is described. A strategic Zika response framework (SRF) for the Gulf States has been developed to meet their urgent need for a collaborative and coordinated response for prevention and spread of ZIKV infection.

Distribution of Aedes mosquito in the Gulf region: Ae aegypti mosquito the primary vector of ZIKV has been found to have existed in some of Gulf countries. This is the same mosquito vector that also transmits dengue, chikungunya, and yellow fever. Sporadic cases of dengue fever, either locally transmitted or imported, including explosive outbreaks of dengue fever, have been reported in the past along the coastal lines of the Red Sea, Arabian Sea, and in Pakistan (WHO, 2011a). One of the largest outbreaks of chikungunya fever has been reported from Yemen in recent time (Malik et al, 2014). These outbreaks have been propagated by high densities of Aedes mosquitoes (Tab. 2). During these outbreaks, increasing the frequency and expanding geographic distribution of both the viruses and mosquito vectors were observed; dengue is now a reportable disease in those countries. Climate conditions in the Middle East are likely to favour the geographic expansion of the Aedes mosquitoes' distribution and subsequently the risk of spread of ZIKV and other arboviral infections such as dengue, chikungunya and yellow fever in the endemic belt of the Middle East cannot be ruled out. A pertinent issue for this region is the need to understand better the epidemiological situation of all hemorrhagic fevers and co-infections of these pathogens including Zika (WHO, 2009). Beside A. aegypti, A. vittatus, which is abundant in Jazan Region southwest of KSA and Jeddah in the western region (Alsheikh et al, 20130; Alikhan et al, 2014) is potentially capable of transmitting Zika.

The evidence for local transmission of dengue fever cases in Jeddah, KSA, was presented by Ghaznawi (1995). In Yemen, the number of dengue cases has increased since the potential DEN-3 epidemic that had taken place in the western AlHudeidah governorate in 2005 (WHO, 2009). Yemen is recently facing a potential surge of suspected dengue fever in six of its governorates; Hodeidah, Taiz, Aden, Lahj, Shabwa and Hadramout (WHO, 2015). During the last decades, many out- 
breaks of the Dengue and chikungunya were reported in Yemen (Al-Garadi, 2015;

Jaawal, 2013; MOPHP, 2014).

Table 1: Countries and territories reporting mosquito-borne ZIKV transmission to10 August 2016 (WHO, 2016a)

\begin{tabular}{|c|c|c|c|}
\hline Classification & WHO Regional Office & Country / territory/area & Total \\
\hline \multirow{3}{*}{$\begin{array}{l}\text { Category 1: Countries } \\
\text { with a first reported } \\
\text { outbreak from } 2015 \\
\text { onwards }\end{array}$} & AFRO & Cabo Verde; Guinea-Bissau & 2 \\
\hline & AMRO/PAHO & $\begin{array}{l}\text { Anguilla; Antigua and Barbuda; Argentina; Aruba; Barbados; Belize; } \\
\text { Bolivia (Plurinational State of), Bonaire, Sint Eustatius and Saba - } \\
\text { Netherlands*; Brazil; Cayman Islands; Colombia; Costa Rica; Cuba; } \\
\text { Curaçao; Dominica; Dominican Republic; Ecuador; El Salvador; } \\
\text { French Guiana; Grenada; Guadeloupe; Guatemala; Guyana; Haiti; } \\
\text { Honduras; Jamaica; Martinique; Mexico; Nicaragua; Panama; } \\
\text { Paraguay; Peru; Puerto Rico; Saint Barthélemy; Saint Lucia; Saint } \\
\text { Martin; Saint Vincent and the Grenadines; Sint Maarten; Suriname; } \\
\text { Trinidad and Tobago; Turks and Caicos; United States of America; } \\
\text { United States Virgin Islands; Venezuela (Bolivarian Republic of) }\end{array}$ & 44 \\
\hline & WPRO & $\begin{array}{l}\text { American Samoa; Fiji; Marshall Islands; Micronesia (Federated } \\
\text { States of); Samoa; Tonga }\end{array}$ & 6 \\
\hline \multicolumn{3}{|l|}{ Subtotal } & 52 \\
\hline \multirow{2}{*}{$\begin{array}{l}\text { Category 2: Countries } \\
\text { with possible endemic } \\
\text { transmission or evidence } \\
\text { of local mosquito-borne } \\
\text { Zika infections in } 2016\end{array}$} & SEARO & Indonesia; Thailand & 2 \\
\hline & WPRO & Philippines; Viet Nam & 2 \\
\hline \multicolumn{3}{|l|}{ Subtotal } & 4 \\
\hline \multirow{4}{*}{$\begin{array}{l}\text { Category 3: Countries } \\
\text { with evidence of local } \\
\text { mosquito-borne Zika } \\
\text { infections in or before } \\
2015 \text {, but without } \\
\text { documentation of cases in } \\
2016 \text {, or outbreak } \\
\text { terminated }\end{array}$} & AFRO & Gabon & 1 \\
\hline & PAHO/AMRO & ISLA DE PASCUA - Chile $* *$ & 1 \\
\hline & SEARO & Bangladesh; Maldives & 2 \\
\hline & WPRO & $\begin{array}{l}\text { Cambodia; Cook Islands**; French Polynesia**; Lao People's } \\
\text { Democratic Republic; Malaysia; New Caledonia; Papua New } \\
\text { Guinea; Solomon Islands; Vanuatu }\end{array}$ & 9 \\
\hline \multicolumn{2}{|l|}{ Subtotal } & & 13 \\
\hline \multicolumn{2}{|l|}{ Total } & & 69 \\
\hline
\end{tabular}

FThis includes confirmed Zika virus cases reported in BONAIRE - Netheriands, SINT EUSTATIUS and SABA - Netherlands.

**These countries and territories have not reported Zika virus cases in 2015 or 2016.

Although the country is endemic to dengue and chikungunya fever with high abundance of competent vectors like the A. aegypti mosquitoes, a seasonal surge is expected during the winter time of the year.

With the current war and frequent displacement of thousands of inhabitants, it is expected that the situation may get worth in the forthcoming months, exposing over 3.2 million inhabitants at a critical risk for ZIKV infection if imported cases were detected in the country (WHO, 2009; 2015).

Although the common vector of dengue virus (A. aegypti) is not found in Kuwait, another potential vector (Ae. caspius) is present; indigenous dengue transmission has not been reported (Salit et al, 1994).

In Oman, four Aedes species were discovered; Ae. aegypti, viz. Ae. vexans arabiensis, Ae. granti and Ae. vittatus. However, indigenous dengue transmission has not been reported in Oman, although it is endemic in neighboring countries viz. Yemen and Jeddah Governorate in Saudi Arabia. Nevertheless, imported cases have been reported for many years (Ministry of Health- Oman, 2010). Based on the available literature, two species of Aedes mosquitoes were found in Qatar; Aedes aegypti (American Army, 1999; Mikhail et al, 2008) and Ae. caspius (Rathor, 1996). 
Table 2: Distribution of significant Aedes mosquitoes in the Gulf States

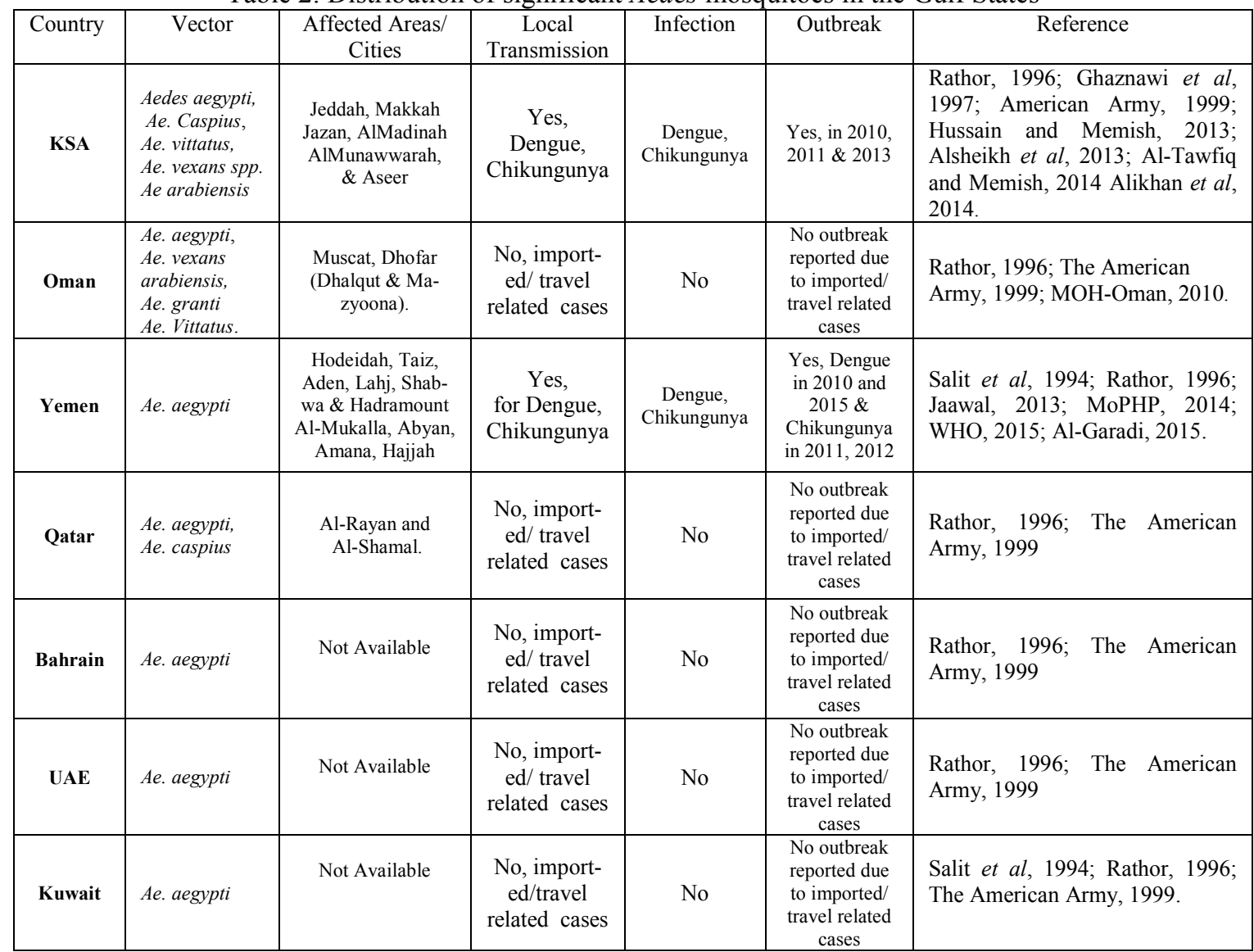

But, dengue travel-related cases have been reported for many years as well. Ae. aegypti was found in UAE and Bahrain (Rathor, 1996; The American Army, 1999), nevertheless, the indigenous dengue transmission has not been reported.

Risk of Zika infection/transmission in the Gulf States: In view of the all available evidence on ZIKV epidemiology and disease presentation, the particular concern is the potential for the establishment of Zika transmission in areas of the Gulf States with the existence of competent vectors like the Red Sea costal part of KSA and Yemen, if the imported cases are detected. In this review, and in order to anticipate future developments, some specific suggestions are made to draw attention to the relevant Gulf States authorities on how to improve the strategy of Zika preparedness and response.

Although geographically far from the Gulf States, Brazil, and South American countries have close connections with the region. Thus, travel-related cases of Zika returning from affected areas (depending on the evolution of the outbreak) can be expected. The widespread distribution of the vectors in the Gulf States increases the risk of onward transmission. Therefore, vigilance regarding any imported cases in the Gulf States needs to be enhanced, including awareness among travel clinics and clinicians, especially of febrile cases not attributable to chikungunya and dengue infections.

This situation is particularly relevant for the Hajj and/or Umrah in Saudi Arabia, which attracts over 2.5 million visitors annually. Saudi Arabia had hosted around 7 million pilgrims from over 180 countries for the Umrah and Hajj between June and September, 2014 (Al-Tawfig and Memish, 2014; MOH, Saudi Arabia, 2016). Putting in mind that Saudi Arabia receives about 7000 pilgrims from Latin America annual- 
ly, we could consider the risk of encountering Zika virus from those participants of Zika epidemic countries during the mass gathering of Umrah and Hajj in this year. The emergence of ZIKV necessitates a serious review of the current vector control strategies being practiced in KSA; a quick Zika risk assessment is urgently needed to set the baseline for future interventions. The capacity of the Laboratories in the region needs to be established to detect ZIKV genome as well.

Amongst the other Zika risk factors in the Gulf States are; high urbanization rates, water storages practices, increasing travels rates, the presence of travel hubs, and human behavior such as wearing no protective clothes during the season of $A e$. aegypti or during outbreaks.

Evidence of the transfusion-transmitted ZIKV infection was not documented. But, viraemic asymptomatic travelers returning from affected areas could potentially transmit the disease through blood donation. Therefore, Gulf States' blood safety authorities need to be advertent and should consider a temporary deferment from blood donation of persons having a travel history to the epidemic areas. The deferment could be set to 4 weeks. In endemic areas with Aedes species like part of KSA and Yemen, measures to sustain blood products and the supply of blood should be considered when designing any preparedness plan to respond to future ZIKV infection outbreaks.

The Strategic Zika Response Framework (SRF) for the Gulf States: WHO has led partners in the creation of a Strategic Response Framework (SRF) for early response activities to the ZIKV epidemic and potential associated neurological complications (WHO, 2016c). It comprises activities in coordination, surveillance, community development, vector control, child and maternal health, public health research, and epidemiological research and development. Gulf States can benefit from this framework (Fig 1).

The implementation of one health approach, the health and environmental sectors are jointly responsible for the leadership and coordination in the Zika response, capacity building, evidence-based interventions, transparency, community engagement, and partnerships are essential principles of Zika response at national level, all should be under a clear chain of command and a unified budget for all authorities involved in the response. Similarly, all Zika communications' efforts need to be jointly coordinated.

The overall goal of the Zika strategic response is to reduce the risk of exposure to ZIKV infection and to prevent its introduction to the Gulf States where competent vector sexist_as well as to rapidly contain any local transmission.

Components of the Strategic Response Framework (SRF) for the Gulf States:

Surveillance: The aim of surveillance is to provide up to date and accurate information on the Ae. aegypti mosquito, ZIKV disease, neurological syndromes and congenital malformations. The focus of ZIKV surveillance is comprised of two parts: Human Surveillance and Vector Surveillance and Control.

Human Surveillance for Zika at the Gulf States: To counteract any incidence of the ZIKA, the epidemiological surveillance system especially syndromic, event-based surveillance (EBS) and laboratory surveillance systems for Zika in the Gulf States need to be strengthened and activated. Also, it is important to monitor the spread of ZIKV infection once autochthonous transmission is confirmed, and monitor for neurological and autoimmune complications. The focus should be on the emergence of clusters of a rash febrile syndrome of unknown etiology (in which dengue, chikungunya, measles, rubella, and parvovirus B19 are ruled out). The symptomatic ZIKA infection usually presents as an influenza-like syndrome, and typical form of 
disease associates a mild fever (between $37.8^{\circ} \mathrm{C} \& 38.5^{\circ} \mathrm{C}$ ), arthralgia, myalgia, conjunctivitis, cutaneous maculopapular rash, headache, and retroocular headaches (Simpson, 1964; Duffy et al, 2009; Heang et al, 2012).
The CDC suggested a possible association between ZIKV infection and microcephaly and other neurological disorders, and gave advises to pregnant women not to travel to countries affected by Zika (Peterson et al, 2016).

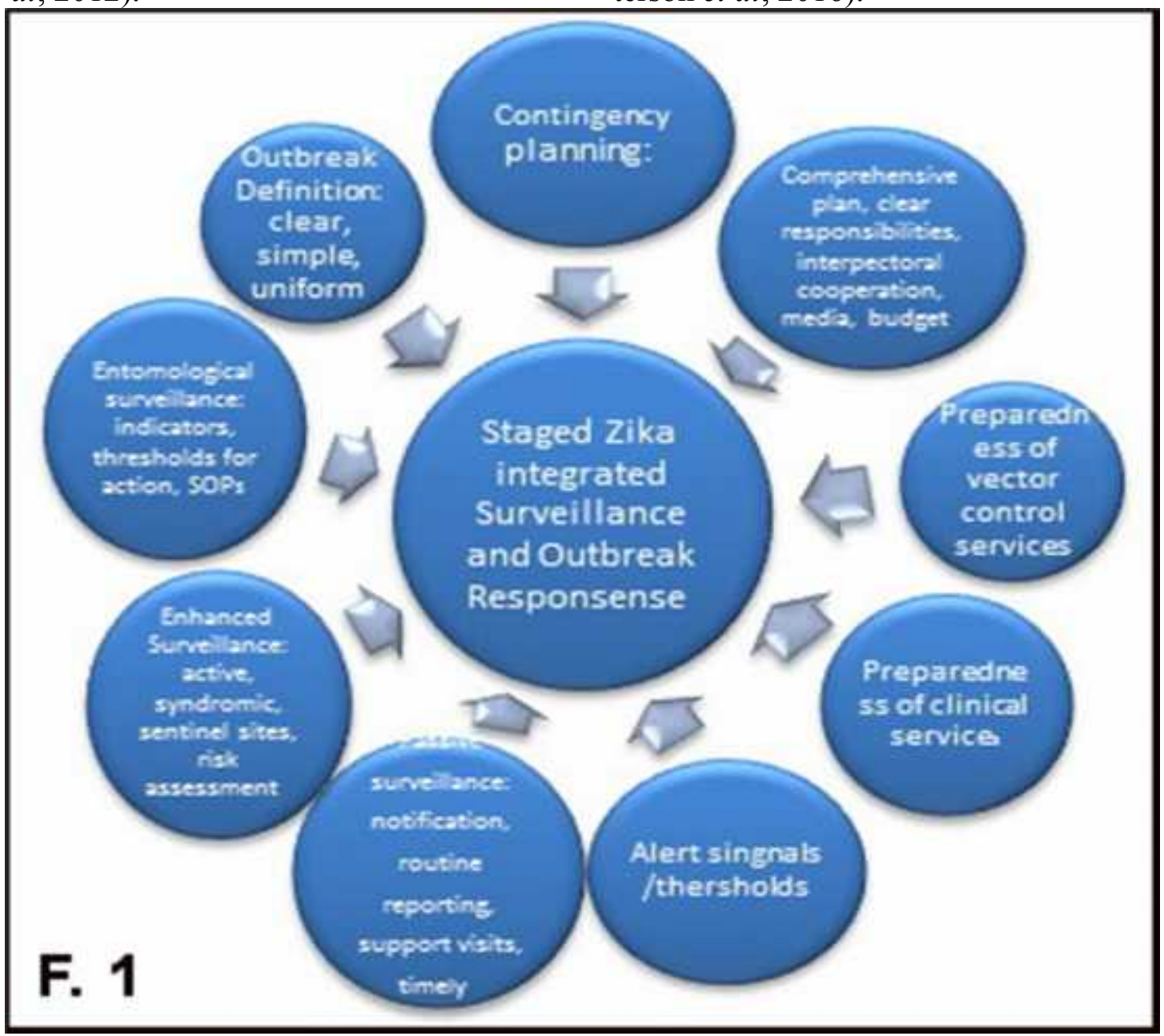

Fig 1: Model of Zika Integrated Surveillance and Outbreak Response (WHO, 2016c)

Testing algorithms for different phases of ZIKV infection need to be used for diagnosis (CDC, 2016). Awareness among healthcare professionals should be raised that the differential diagnosis of febrile and sub-febrile patients with a rash should include ZIKV infection, especially in patients returning from affected areas by this virus. Monitoring environmental and climatic precursors of this virus and its vectors linked to integrated surveillance of human cases and vectors and can help counteract potential impacts (Semenza et al, 2013; Nichols et al, 2014). Routine sentinel surveillance (using fever syn- dromic surveillance) for arboviral diseases including ZIKV within an integrated disease surveillance system need to be established and strengthened (WHO, 2011b). Any increase in non-malaria, non- dengue, and non-chikungunya fever cases should trigger the alert system and samples should be tested for the ZIKV infection (WHO, 2011b).

Entomological Surveillance: In some regions of Saudi Arabia (Jeddah, Mecca, Medina), nearly two-thirds of Ae. aegyp$t i$ larvae are present in indoor habitats throughout the year. However, Larvae density is variable and decreases in the 
summer months before October. Dengue seroprevalence in these regions is ranging from $32 \%$ to $57 \%$ among total patients seeking medical consultations (Aziz et al, 2012; Alhaeli et al, 2015). A seroprevalence of $31.7 \%$ for DENV specific IgG was found among 965 persons in Jazan Region southwest of Saudi Arabia (AlAzragi et al, 2013).

Baseline surveys should be conducted in all areas with a history of Ae. aegypti and Ae. vittatus in the Gulf States. This should include breeding sites for immature stages, as well as, adult mosquitoes, epidemiological data, and ecological indicators. Immature stage survey indices should be determined periodically for every location as follows; House Index (HI; percentage of houses with at least one positive container), Container Index (CI; percentage of all containers with water that are larva/pupa positive), and Breteau Index (BI; number of positive containers per 100 houses (WHO 2009). Densities of the adult female of Aedes mosquitoes should also be determined for each location. Locations with high immature stage indices $(5 \%$ for each of $\mathrm{HI}$ and $\mathrm{BI}$, and $10 \%$ for $\mathrm{CI}$ ) and high female densities (two or more females per sticky gravid traps per week) (Ritchie et al, 2004) during outbreaks with ZIKV or other arboviral diseases should be considered as vector hot spots (sentinel sites) with top priorities for control activities and periodical monitoring. Outbreak areas should be intensively screened for breeding sites and febrile cases, and mosquito control measures (source reduction for the immature stages and fogging of the adults at high densities areas) should be implemented for 3-4 weeks until cases declined significantly (WHO, 2011b).

Integrated vector surveillance needs to be established according to the following procedures: Any notification of a laboratory-confirmed locally acquired ZIKV case would trigger immediate entomological and epidemiological investigations to guide vector control programs and to assess the autochthonous transmission. These investigations and control activities should include (Paty et al, 2014): (1) the search and finding of any active case in the vicinity of the case's residence and/or any other visited areas by the case; (2) the viraemic case should recommended a suitable personal protection measure; (3) suspected cases should be screened by the health professionals; (4) carrying out perifocal mosquito control measures within 200 meters of the patient's residence such as fogging or misting at the adult Aedes mosquitoes and destruct their breeding sites; (5) giving the public some information on personal protection options and how to destruct and reduce the mosquito breeding sites. Also, the areas with high mosquito adults' density and high household immature stage indices should be controlled periodically even though no case of ZIKV has been declared.

Public education and community mobilization: Raising increasing knowledge and awareness among the general public, practitioners, and public health policymakers about Ae. aegypti mosquitoes and their relationship with ZIKV should be a top priority for the health authorities in the Gulf States. All the Ministries of Health, as well as, Ministries of Municipals in the Gulf States need to launch different interventions and workshops to increase the knowledge about ZIKV and biology and ecology of the Aedes mosquitoes in the community. Regular interventions and education programs need to be conducted out at different levels to highlight the importance of personal practices and behaviors in preventing ZIKV. Engage communities to communicate the risks associated with ZIKV disease and promote healthy behaviors, reduce anxiety, address stigma, dispel rumors and cultural misperceptions.

Prevention and Travel Health: Prevention of exposure through vector abatement and personal protection are significant 
components of effective intervention strategies. Additionally, integrated vector surveillance of competent mosquito vectors is imperative for effective control and prevention of ZIKV. As Hajj and Umrah are by far mass gathering, a combination of measures is needed at personal, community, and policy levels. Hajj authorities have taken proactive vector control measures against the emergence of dengue and chikungunya. Given that pilgrim flow to Saudi Arabia is continuous, these efforts will help minimize any future transmission of ZIKV as well. ${ }^{30}$ Options for personal mosquito bite protection may include, but not limited to, the use of insect repellents, insecticide-treated mosquito nets, protective clothing, including long-sleeved shirts and trousers, and air conditioning in residences. Reinforcing advice on personal protection at points of departure and arrival in home and host countries is crucial in preventing the human-vector contacts and bites. It is also crucial to increase the availability and distribution points of the methods to prevent mosquito bites.

Research and Development: To answer many questions, further laboratory and epidemiological investigations need to be conducted to establish: the relationship between neurological and auto-immune complications and ZIKAV infection, notably with other etiologies; evidence about transmission cycle(s), viral strain genetic characteristics, vectors and reservoir hosts to assess its implications for public health; human risk factors and previous infection with other infectious agents; cross-reactivity of Zika serology with other Flavivirus infections; possibility detection of ZIKV genome using urine samples and other Flavivirus infections. This information is considered to be the key for proper preparedness and response to outbreaks. As ZIKV is an emerging pathogen, it is imperative to investigate any significant outbreaks carefully to assess better the consequences for public health and the risk of spread. Researches on vector biology, ecology, behavior, and interacting between vector-virus and -host are also needed.

\section{Conclusion}

ZIKV as a vector-borne disease would remain a significant challenge to public health in the Gulf States. Vigilance needs to be enhanced to detect any imported cases of ZIKV infection in the Gulf States, in particular where potential vectors are present, specifically Saudi Arabia and Yemen, where Ae. aegypti is well entrenched.

To prevent local transmission, early detection of cases is essential to reduce the risk of autochthonous transmission. Countries need to implement a quick ZIKV assessment to set a baseline for future interventions. Health care Providers should be aware of the evolution of ZIKV-affected areas and should use their differential diagnosis to detect ZIKV infection in the travelers from those areas. Fever and/or macular or popular rash not attributable to chikungunya or dengue infection among travelers returning from affected areas should have more investigations for ZIKV infection. The laboratory capacity to confirm suspected ZIKV infections should be strengthened. Blood Banks need to be vigilant and might wish to consider deferral of donors with relevant travel history. Protection against mosquito bites and vector control are the corner's stone in prevention of ZIKV infection in the Gulf States. A coordinated response of all partners in the Gulf States across sectors and services at national, as well as, regional levels is required.

Competing interests: The authors declared no competing interest.

\section{References}

Al-Azraqi TA, EIMekki AA, Mahfouz AA, 2013: Seroprevalence of dengue virus infection in Aseer and Jizan regions, Southwestern Saudi Arabia. Trans. R. Soc. Trop. Med. Hyg. 107, 6:368-71.

Alera, MT, Hermann, L, Tac-An, IA, Klungthong, C, Rutvisuttinunt, $\mathrm{W}$, et al, 2015: 
Zika virus infection, Philippines, 2012 Emerg. Infect. Dis. 21:722-4.

Al-Garadi, MA, 2015: Epidemiological review of dengue fever in Yemen. Int. J. Adv. Res. 3, 7:1578-84.

Alhaeli, A, Bahkali, S, Ali, A, Househ, MS, El-Metwally, AA, 2015: The epidemiology of dengue fever in Saudi Arabia: a systematic review. J. Infect. Publ. Hlth. 9, 2:117-24.

Alikhan, M, Al Ghamdi, K, Mahyoub, JA, 2014: Aedes mosquito species in western $\mathrm{Sa}-$ udi Arabia. J. Insect Sci. 20:14-69.

Alsheikh, AA, Zafer, MH, Anaami, AG, Solan, YM, Noureldin, EM, et al, 2013: Potential mosquito vectors of arboviral diseases in Jazan Region, Saudi Arabia. Biosci. Biotech. Res. Comm. 6, 2:142-9.

Al-Tawfiq, JA, Memish, JA, 2014: Mass gathering medicine; 2014 Hajj and Umra preparation as a leading example. Int. J. Infect. Dis. 27:26-31.

Aziz, AT, Dieng, H, Ahmad, AH et al, 2012: Household survey of container-breeding mosquitoes and climatic factors influencing the prevalence of Aedes aegypti (Diptera: Culicidae) in Makkah City, Saudi Arabia. Asian Pac. J. Trop. Biomed. 2:849-57.

Baronti, C, Piorkowski, G, Charrel, RN, Boubis, L, Leparc-Goffart, I, et al, 2014: Complete coding sequence of Zika virus from a French Polynesia outbreak in 2013. Genome Announc. 2014 Jun 5;2(3). pii: e00500-14. doi: 10.1128/genomeA.00500-14.

Buathong R, Hermann, L, Thaisomboonsuk, B, Rutvisuttinunt, W, et al, 2015: Detection of Zika Virus Infection in Thailand, 20122014 Am. J. Trop. Med. Hyg, 93:380-3.

Burdino, E, Milia, MG, Sergi, G, Gregori, G, Allice, T, et al, 2011: Diagnosis of dengue fever in North West Italy in travelers from endemic areas: a retrospective study. J. Clin. Virol. 51, 4:259-63.

CDC, 2016: Diagnostic Tests for Zika Virus. Available at:www.cdc.gov/zika/hc-providers/ testing-for-zikavirus.html

Dick, GW, 1952: Zika virus. II. Pathogenicity and physical properties. Trans. R. Soc. Trop. Med. Hyg. 46:521-34.

Duffy MR, Chen TH, Hancock WT, Powers AM, Kool JL, Lanciotti RS, et al, 2009: Zika virus outbreak on Yap Island, Federated States of Micronesia. N. Engl. J. Med. 360, 24:2536-43.
Ghaznawi, HI, Al-Khateeb, TO, Akbar, N, Afifi, H, Nasser, A, 1997: Surveillance for dengue fever in Jeddah. East. Mediterr. Hlth. J. 3:567-70.

Heang, V, Yasuda, CY, Sovann, L, Haddow, AD, Travassos da Rosa, AP, et al, 2012: Zika virus infection, Cambodia, 2010. Emerg. Infect. Dis. 18, 2:349-51.

Hussain, R, Alomar, I, Memish, ZA, 2013: Chikungunya virus: emergence of an arthritic arbovirus in Jeddah, Saudi Arabia. East. Mediterr. Hlth. J. 19, 5:506-8.

Jaawal, AA, 2013: Dengue Fever or Chikungunya Outbreak? Hodeidah Governorate, Yemen, April 2012. $1^{\text {st }}$ Arab World Conf. Publ. Hlth. Dubai, UAE:4-6 April, 2013.

Macnamara, FN, 1954: Zika virus: a report on three cases of human infection during an epidemic of jaundice in Nigeria. Trans. R. Soc. Trop. Med. Hyg. 48:139-44.

Malik MR, Mnzava, A, Mohareb, E, Zayed, A, Al Kohlani, A, et al, 2014: Chikungunya outbreak in Al-Hudaydah, Yemen, 2011: Epidemiological characterization and key lessons learned for early detection and control. J. Epidemiol. Global Hlth. 4, 3:203-11.

Mikhail, MW, Al-Bursheed, KhM, Abd-ElHalim, AS, Morsy, TA, 2008: Studies on mosquito borne diseases in Egypt and Qatar. J. Egypt. Soc. Parasitol. 39, 3:745-56.

Ministry of Health, Oman, 2010: Community Health \& Disease Surveillance Newsletter, Special Issue on: Emerging Infectious Diseases Part-1, Vol. 19, Issue 4, by Directorate General of Health Affairs, Ministry of Health, Oman.

MOH, Saudi Arabia, 2016: Hajj 1436, Health Regulations. http://www.moh. gov.sa/en/ hajj/pages/healthregulations.aspx.

MOPHP, 2014: Reporting System of Infectious Diseases; Ministry of Public Health and Population, Republic of Yemen.

Nichols, GL, Andersson, Y, Lindgren, E, Devaux, I, Semenza, JC, 2014: European monitoring systems and data for assessing environmental and climate impacts on human infectious diseases. Int. J. Environ. Res. Publ, Hlth. 11, 4:3894-936.

Olson JG, Ksiazek TG, Suhandiman, Triwibowo, 1981: Zika virus, a cause of fever in Central Java, Indonesia. Trans. R. Soc. Trop. Med. Hyg. 75, 3:389-93. 
Paty, MC, Six, C, Charlet, F, Heuzé, G, Cochet, A, et al, 2014: Large number of imported chikungunya cases in mainland France, 2014: A challenge for surveillance and response; Euro Surveill. 19, 28:20856. http://dx. doi.org/10.2807/1560-7917.

Petersen, EE, Staples, JE, Meaney-Delman, D et al, 2016: Interim guidelines for pregnant women during a Zika virus outbreak, United States: MMWR Morb Mortal Wkly Rep. 65:30-3.

Rathor, HR, 1996: The role of vectors in emerging and re-emerging diseases in the Eastern Mediterranean Region. East. Mediterr. Hlth. J. 2:61-7.

Ritchie, SA, Long, S, Smith, G, Pyke, A, Knox, TB, 2004: Entomological investigations in a focus of dengue transmission in Cairns, Queensland, Australia, by using the sticky ovitraps. J. Med. Entomol. 41:1-4.

Salit, A, Zakaria, M, Balba, M, Zaghloul, T, 1994: The mosquito fauna of Kuwait. J. Uni. Kuwait (Science), 1994, 21:77-84.

Samarasekera, U, Triunfol, M, 2016: Concern over Zika virus grips the world. Lancet. 387, 10018: 521-4.

Semenza, JC, Sudre, B, Oni, T, Suk, JE, Giesecke, J, 2013: Linking environmental drivers to infectious diseases: the European environment and epidemiology network. PLoS Negl Trop Dis 2013; 7(7): e2323. http://dx. doi.org/10.1371/journal.pntd.0002323.

Simpson, DI, 1964: Zika Virus Infection in Man. Trans R Soc Trop Med Hyg. 58:335-8.

Smithburn, KC, 1952: Neutralizing antibodies against certain recently isolated viruses in the sera of human beings residing in East Africa. J. Immunol. 69, 2:223-34.

The American Army, 1999: Regional Disease Vector Ecology Profile: The Middle East. Armed Forces Pest Management Board, Washington DC, Oct. Web link http://www.Afpm b.org/sites/default/files/pubs/dveps/mid_east.p df and: http://www.afpmb.org/content/diseasevector-ecology-profiles
Tognarelli, J, Ulloa, S, Villagra, E, Lagos, J, Aguayo, C, et al, 2015: A report on the outbreak of Zika virus on Easter Island, South Pacific, 2014. Arch. Virol. 161, 3:665-8.

WHO, 2009: Dengue guidelines for diagnosis, treatment, prevention and control: New Edition. Geneva, Switzerland.

WHO, 2011a: Technical paper Dengue: call for urgent interventions for a rapidly expanding emerging disease, EM/RC58/3 2011.

WHO, 2011b: Report on the Sub-regional meeting on dengue fever in the Red Sea rim Cairo, Egypt 20-22 July 2011.

WHO, 2016a: Situation report: Zika virus microcephaly Guillain-barré syndrome 11 august:http://apps.who.int/iris/bitstream/10665/2 49518/1/zikasitrep11Aug2016-eng.pdf?ua=1

WHO, 2016b: Statement on the first meeting of the International Health Regulations (2005) (IHR 2005) Emergency Committee on Zika virus and observed increase in neurological disorders and neonatal malformations. http://www.who.int/mediacentre/news/statements/20 16/1st-emergency-committee-zika/en/

WHO, 2016c: Zika Outbreak: WHO's Global Emergency Response Plan Global prevention and control strategy, http://www.who.int/emergencies/zika-virus/response/en/

WHO/EMRO, 2015: Weekly Epidemiological Monitor: WHO/EMRO, Cairo, Egypt. Vol. 8, Issue 25 Sunday 21 June 2015,

Zanluca, C, de Melo, VCA, Mosimann, AL $P$, dos Santos, GIV, dos Santos, CND, et al, 2015: First report of autochthonous transmission of Zika virus in Brazil. Mem. Inst. 393 Oswaldo Cruz 110:569-72. 